\title{
RUMAH SAKIT UMUM Kelas B Dengan KonSEP GREEN HoSPITAL DI KOTA DEPOK
}

\author{
Fanny Zulkarnain, Agus Heru Purnomo, B. Heru Santosa Soemarno \\ Program Studi Arsitektur \\ Fakultas Teknik \\ Universitas Sebelas Maret Surakarta \\ Email: zulkarnainfanny@gmail.com
}

\begin{abstract}
Health care quality is one of the factor that determines the citizens' standard of living. However, the development of Depok City as a supporting city of Jakarta is not followed by the development of health care facilities because to this day, Depok still has a shortage of hospital facilities. The hospital needed by Depok City must be able to accommodate high patient loads, capable of serving 10 major illness Depok City residents had, and it's a green hospital in accordance with the direction of the Directorate General of Health and Community Development Efforts Republic of Indonesia. Green hospitals are hospitals that utilize the potential of nature, reducing the negative impact of the hospital to the environment, and inventing a good quality healing environtment in hospitals. The concept of green hospitals is achieved through the implementation of elements of the green hospital concept in the design process of this hospital which is; a suitable location, selection of materials that are environmentally friendly, water conservation in hospitals, waste treatment in an integrated manner, utilization of alternative energy, energy efficiency in hospitals, increasing service performance and efficiency, as well as the embodiment of healing environtment in a hospital to speed up patient recovery. In addition to the implementation of the element of green hospital concept, the hospital is also implementing hospital design standards that apply in Indonesia. The hospital is expected to be one of the first hospital in Indonesia to implement the concept of green hospital holistically.
\end{abstract}

Keywords: Depok City, Green Hospital Concept, Hospital Standard

\section{PENDAHULUAN}

Kualitas pelayanan kesehatan merupakan salah satu faktor yang menentukan taraf hidup seorang warga negara. Perkembangan Kota Depok sebagai kota penunjang DKI Jakarta tidak diikuti dengan perkembangan fasilitas pelayanan kesehatan. Kota Depok masih kekurangan tempat tidur rumah sakit sebanyak 980 buah, dengan laju pertumbuhan penduduk mencapai $4 \%$ (sirs.buk.depkes.go.id) maka lima tahun ke depan Kota Depok harus menambah 393 tempat tidur rumah sakit, sedangkan pertumbuhan rumah sakit di Kota Depok lima tahun kebelakang hanya bertambah dua rumah sakit. Laju pertumbuhan penduduk dan pertumbuhan rumah sakit ini tidak seimbang, sehingga Kota Depok butuh rumah sakit baru yang mampu menampung banyak pasien sekaligus mampu melayani penyembuhan penyakit-penyakit terbanyak yang diderita warga Kota Depok.
Rumah sakit yang direncanakan harus memiliki standar yang tinggi, baik dalam kualitas maupun efisiensi. Rumah sakit harus dapat meningkatkan efisiensi pelayanan dengan menerapkan pelayanan satu pintu, efisiensi lahan dengan perancangan dan sirkulasi optimal, serta efisiensi pemulihan pasien dengan menerapkan alat medis yang canggih dan menerapkan konsep healing environtment di dalam rumah sakit, yaitu dengan perwujudan taman dan penggunaan elemen alami di dalam perancangan. Hal tersebut disebabkan karena tingkat stress pasien paling tinggi jika hanya dapat melihat beton atau dinding di sekelilingnya dan paling rendah jika melihat taman berbunga (Nakamura \& Fuji, 1990-1992 dalam Ulrich, 2002). Pasien yang memiliki pemandangan taman juga dapat sembuh sehari lebih cepat, membutuhkan obat penghilang rasa sakit lebih sedikit, dan mengalami komplikasi pasca operasi lebih sedikit dibanding pasien yang 
hanya melihat beton atau dinding (Ulrich, 2002).

Rumah sakit yang direncanakan juga merupakan rumah sakit yang peduli terhadap lingkungan karena rumah sakit memiliki dampak yang sangat besar terhadap lingkungan sekitar maupun lingkungan global, sehingga rumah sakit yang direncanakan akan berupaya mengurangi dampak negatif ke lingkungan sekitar, baik secara aktif maupun pasif.

Perwujudan green hospital di Indonesia juga merupakan target Direktorat Jenderal Bina Upaya Kesehatan bahwa pada tahun 2020 seluruh rumah sakit di Indonesia telah menerapkan konsep green hospital. Rumah sakit yang direncanakan ini diharapkan dapat menjadi salah satu rumah sakit pertama yang menerapkan konsep green hospital secara holistik.

\section{METODE}

A. Macam dan Teknik Pengumpulan Data Data yang dikumpulkan yakni data terkait proses perancangan rumah sakit seperti data lokasi dan tapak, data kegiatan di rumah sakit dan kebutuhan ruang rumah sakit. Selain itu juga terdapat tinjauan pustaka terkait permassaan rumah sakit, sistem struktur, sistem utilitas, strategi peningkatan performansi rumah sakit, serta strategi green hospital yang akan diterapkan di rumah sakit. Semua data tersebut diperoleh dari tinjauan pustaka serta wawancara kepada pelaku kegiatan maupun perancang rumah sakit.

\section{B. Metode Analisis Data}

Analisis perencanaan dilakukan dengan mengidentifikasi masalah yang ada pada konsep perancangan rumah sakit umum kelas B dengan konsep green hospital di Kota Depok yang diselesaikan dengan menerapkan konsep green hospital yang kemudian digabungkan dengan standar perancangan rumah sakit di Indonesia yang diatur oleh Kementrian Kesehatan Republik Indonesia. Konsep green hospital yang diterapkan mengacu pada tujuh elemen green hospital yaitu kesesuaian lokasi, pemilihan material yang ramah lingkungan, konservasi air, penangangan limbah yang terpadu, pemanfaatan energi alternatif, efisiensi energi, serta peningkatan performansi yang akan diwujudkan dalam perancangan rumah sakit secara holistik yaitu pada tapak, massa, ruang, kegiatan, struktur dan utilitas.

\section{ANALISIS}

\section{A. Analisis Tapak}

Tapak yang difungsikan untuk rumah sakit harus memenuhi beberapa persyaratan berdasarkan pedoman perancangan rumah sakit dan konsep green hospital.

a. Tujuan: Mendapatkan lokasi tapak yang sesuai dengan kriteria perancangan.

b. Dasar Pertimbangan: Tanah bukan merupakan lahan produktif, dekat dengan pengguna rumah sakit, aksesibiltas untuk jalur transportasi dan komunikasi, kontur tanah datar, lahan cukup untuk fasilitas parkir, tersedia jaringan utilitas publik, dekat dengan sistem utilitas kota, sesuai dengan regulasi pengelolaan kesehatan lingkungan, bebas dari polusi kebisingan, asap, uap, dan gangguan lain, serta memiliki kadar polutansi air dan udara rendah.

\section{B. Analisis Pencapaian}

Pencapaian ke rumah sakit harus komunikatif, mudah diakses, dan memudahkan sirkulasi pengguna.

1. Tujuan: Menentukan main entrance utama, main entrance IGD, menentukan side entrance.

2. Dasar Pertimbangan: Kemudahan akses, kesesuaian fungsi, komunikatif.

3. Proses Analisis:

\section{Main Entrance (ME)}

Berada di jalan utama, di depan massa utama rawat jalan (Gambar 1).

Main Entrance IGD

Berada di sisi ujung tapak, pada sisi tapak yang pertama dilewati sesuai dengan arus lalu lintas (Gambar 1).

Side Entrance (SE)

Berada di jalan sekunder, tidak di muka bangunan utama (Gambar 1). 
Fanny Z, Agus H P, B. Heru S S, Rumah Sakit Umum Kelas B...

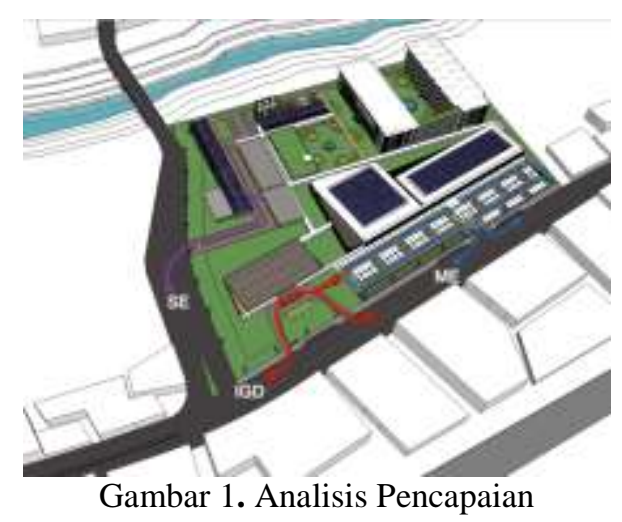

C. Analisis Pemintakatan (Penzoningan) Pemintakatan rumah sakit berfungsi untuk memisahkan fungsi-fungsi di dalam rumah sakit. Penentuan zona fungsi ini diatur dalam pedoman perancangan rumah sakit yang diterbitkan oleh Kementrian Kesehatan Republik Indonesia.

1. Tujuan: Menentukan zona pelayanan non-keperawatan, pelayanan keperawatan, penunjang medik, penunjang umum, dan servis.

2. Dasar Pertimbangan: Persyaratan ruang, kemudahan akses, kemudahan sirkulasi, kebisingan, dan privasi tapak.

3. Proses Analisis: Poin-poin dasar pertimbangan saling dikaitkan dan diterjemahkan kedalam tapak sehingga diperoleh hasil pemintakatan sebagai berikut (Gambar 2).

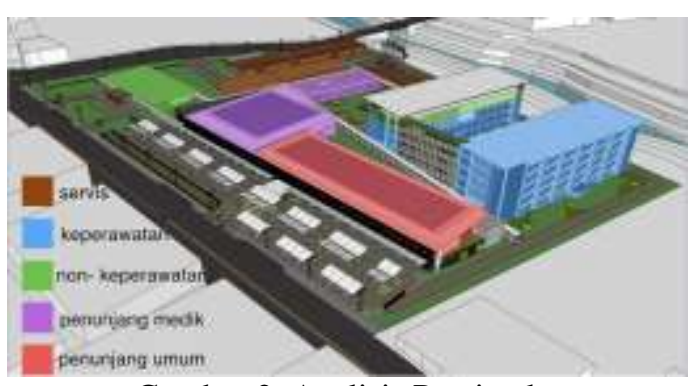

Gambar 2. Analisis Pemintakatan

Hasil analisis pemintakatan tersebut kemudian diterjemahkan menjadi kebutuhan ruang pelayanan nonkeperawatan, pelayanan keperawatan, penunjang medis, penunjang umum, dan servis (Tabel 1).
Tabel 1.Kebutuhan Ruang

\begin{tabular}{|c|c|c|}
\hline KELOMPOK & RUANG & PRIVASI \\
\hline \multirow{4}{*}{$\begin{array}{l}\text { Pelayanan } \\
\text { Non- } \\
\text { Keperawatan }\end{array}$} & IGD & Semi-Privat \\
\hline & Rawat Jalan & Publik \\
\hline & Inst.Bedah & Privat \\
\hline & $O b-G y n$ & Privat \\
\hline \multirow{3}{*}{$\begin{array}{l}\text { Pelayanan } \\
\text { Keperawatan }\end{array}$} & Rawat Inap & Privat \\
\hline & ICU/ICCU & Privat \\
\hline & High Care & Privat \\
\hline \multirow{7}{*}{$\begin{array}{l}\text { Penunjang } \\
\text { Medik }\end{array}$} & Lab / Patologi & Privat \\
\hline & Bank Darah & Semi-Privat \\
\hline & Rehab Medik & Semi-Privat \\
\hline & Radiologi & Privat \\
\hline & Hemodialisa & Privat \\
\hline & Farmasi & Publik \\
\hline & Kantor & Semi-Privat \\
\hline \multirow{2}{*}{$\begin{array}{l}\text { Penunjang } \\
\text { Umum }\end{array}$} & Arsip & Privat \\
\hline & IPAL & Semi-Privat \\
\hline \multirow[t]{5}{*}{ Servis } & IPSRS & Semi-Privat \\
\hline & Dapur & Semi-Privat \\
\hline & Laundry & Semi-Privat \\
\hline & Inst. Jenazah & Semi-Privat \\
\hline & CSSD & Semi-Privat \\
\hline
\end{tabular}

D. Analisis Bentukan Massa dan Tampilan Bangunan

1. Analisis Bentukan Massa

Massa dasar berbentuk segi empat karena segi empat merupakan bentuk paling efisien. Konsep bentukan massa yang diterapkan yaitu tipe compact courtyard (Gambar 3) karena cocok diterapkan pada tapak yang luas, dapat mengoptimalkan pencahayaan alami, serta lebih mendukung proses penyembuhan dengan adanya taman yang mengelilingi massa. Sedangkan untuk pengembangan massa secara vertikal menerapkan tipe articulated slab on podium (Gambar 3) yang memisahkan fungsi antar lantai atau massa dan juga memisahkan fungsi sirkulasi vertikal dari fungsi ruang sehingga kebisingan dapat diminimalisir demi tercipta healing environtment yang baik. Hasil analisis 
pengembangan massa rumah sakit diilustrasikan pada Gambar 4.
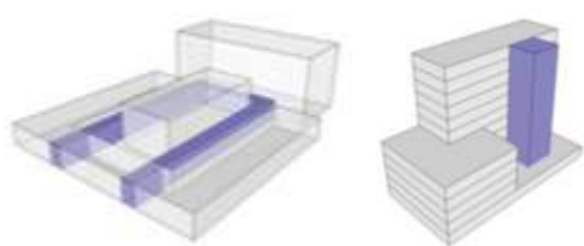

Gambar 3. Compact Courtyard (Kiri) dan Articulated Slab on Podium (Kanan)

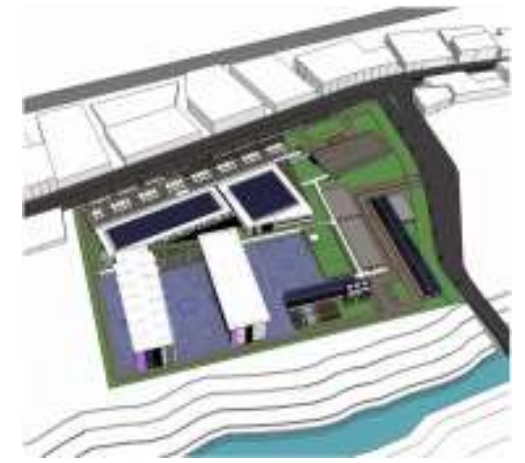

Gambar 4. Pengembangan Massa Rumah Sakit

2. Tampilan Bangunan

Tampilan bangunan pada fasilitas kesehatan ini harus memenuhi kriteria untuk dapat membantu mewujudkan healing environtment. Dasar pertimbangan pemilihan fasad yaitu aspek estetika, akses cahaya matahari, akustik ruang, infiltrasi udara, dan pertimbangan keamanan. Berdasarkan pertimbangan tersebut, fasad rumah sakit menerapkan fasad vegetasi rambat dengan light shelf yang dapat memantulkan dan memasukkan cahaya matahari ke dalam ruangan (Gambar 5). Light shelf yang diaplikasikan merupakan sebuah bidang pantul berbahan dasar GRC yang memiliki warna cerah agar proses pemantulan cahaya optimal. Vegetasi rambat yang diaplikasikan pada fasad selain memberi kesan natural juga dapat berfungsi sebagai tabir sinar dan berfungsi sebagai alat filtrasi udara (Meur, 2014 dalam Sourceable.net)

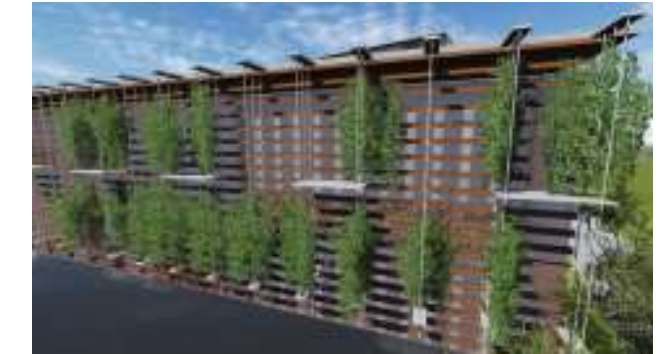

Gambar 5. Fasad Vegetasi Rambat Dengan Light Shelf

\section{F. Analisis Klimatologi}

1. Tujuan: Menentukan respon desain yang sesuai analisis klimatologi.

2. Dasar Pertimbangan: Arah terbitterbenam matahari, arah angin, kebisingan, dan view.

3. Proses Analisis (lihat pada Tabel 2).

Tabel 2. Analisis Klimatologi

\begin{tabular}{|l|l|l|}
\hline ASPEK & ANALISIS & \multicolumn{1}{c|}{ RESPON } \\
\hline Matahari & $\begin{array}{l}\text { Optimalisasi } \\
\text { penerimaan } \\
\text { sinar } \\
\text { matahari pagi } \\
\text { di timur, } \\
\text { menghindari } \\
\text { sinar } \\
\text { matahari } \\
\text { sore. }\end{array}$ & $\begin{array}{l}\text { Area timur tidak } \\
\text { terhalang, } \\
\text { orientasi taman } \\
\text { ke timur. }\end{array}$ \\
\cline { 3 - 3 } & $\begin{array}{l}\text { Tabir sinar di } \\
\text { bagian barat, } \\
\text { vegetasi peneduh. }\end{array}$ \\
\cline { 3 - 3 } & $\begin{array}{l}\text { Aplikasi atrium, } \\
\text { pergola. }\end{array}$ \\
\hline Angin & $\begin{array}{l}\text { Arah angin } \\
\text { tenggara ke } \\
\text { barat laut } \\
\text { atau } \\
\text { sebaliknya } \\
\text { tergantung } \\
\text { musim. }\end{array}$ & $\begin{array}{l}\text { Bangunan } \\
\text { diposisikan agar } \\
\text { dialiri angin. }\end{array}$ \\
\cline { 3 - 4 } & $\begin{array}{l}\text { Massa tipis dan } \\
\text { panjang. }\end{array}$ \\
\cline { 3 - 4 } & $\begin{array}{l}\text { Vegetasi } \\
\text { pengarah dan } \\
\text { penyaring angin. }\end{array}$ \\
\hline Kebising \\
an & $\begin{array}{l}\text { Kebisingan } \\
\text { dari jalan } \\
\text { raya di barat } \\
\text { tapak. }\end{array}$ & $\begin{array}{l}\text { Memundurkan } \\
\text { jarak bangunan } \\
\text { dari jalan, } \\
\text { vegetasi di barat } \\
\text { sebagai barier. }\end{array}$ \\
\hline View & $\begin{array}{l}\text { View ke arah } \\
\text { Kali } \\
\text { Ciliwung di } \\
\text { sisi timur. }\end{array}$ & $\begin{array}{l}\text { Sisi timur tidak } \\
\text { terhalang. }\end{array}$ \\
\cline { 3 - 4 } & $\begin{array}{l}\text { Orientasi taman } \\
\text { ke sisi timur. }\end{array}$ \\
\cline { 3 - 4 } & $\begin{array}{l}\text { Taman buatan } \\
\text { sebagai alternatif } \\
\text { view in-site. }\end{array}$ \\
\hline
\end{tabular}


G. Analisis Sirkulasi dan Tata Lansekap

1. Sirkulasi antar fasilitas yang diterapkan yakni konsep sirkulasi lintasan umpan balik, yaitu kegiatan berasal dari satu pusat kegiatan lalu menyebar ke berbagai kelompok kegiatan tetapi masih memungkinkan untuk kembali ke pusat kegiatan. Pola sirkulasi ini sesuai dengan konsep pelayanan satu pintu dari rumah sakit yang direncanakan. Pola sirkulasi ini didukung dengan adanya simpul sirkulasi (hub dan atrium) yang berguna untuk mengurangi kepadatan di pusat kegiatan.

2. Pengolahan lansekap dilakukan demi membantu mewujudkan konsep green hospital di rumah sakit. Melalui pengolahan lansekap diharapkan healing environtment pada rumah sakit dapat terwujud, dan dapat menurunkan tingkat stress serta mempercepat kesembuhan pasien (Ulrich, 2002).

a. Sirkulasi taman yang digunakan yaitu pola jalur berkeliling, karena taman di rumah sakit difungsikan sebagai tempat terapi pasien, sehingga kebutuhan kegiatan tersebut bukanlah kecepatan atau kemudahan sirkulasi, namun kualitas ruang di sekitarnya. Taman yang direncanakan memiliki sirkulasi berkeliling dengan elemen-elemen vegetasi, kolam, dan batu-batuan untuk membentuk sebuah healing environtment yang baik.

b. Penerapan elemen hardscape pada rumah sakit dimanfaatkan untuk pendukung kegiatan sirkulasi, serta memberi perkuatan terhadap karakter alami dan estetika bangunan. Hardscape yang diterapkan merupakan material ramah hujan seperi grass block, material alami seperti batu bertekstur, rumput, serta elemen air yang semuanya mendukung terwujudnya healing

environtment yang baik.

b. Elemen softscape pada rumah sakit merupakan vegetasi yang tidak memicu alergi, mampu menangkap banyak air hujan, mereduksi panas, mereduksi polusi udara, serta mampu mereduksi banyak $\mathrm{NO}_{\mathrm{x}}$ dan $\mathrm{CO}_{\mathrm{x} . \text { Vegetasi yang }}$ direncanakan berupa vegetasi peneduh seperti Flamboyan, Trengguli, dan Kasia Multijuga, vegetasi peredam bising seperti Sawo Kecik, Bambu Hias, dan Jakaranda, serta vegetasi untuk estetika seperti Soka, Kembang Jepun, dan Kembang Sepatu (Surtowinoto, 1997).

\section{H. Analisis Ruang dan Elemen Ruang}

1. Ruang Rawat Inap Kelas 1

Ruang rawat inap kelas 1 (Gambar 6) pada rumah sakit mengambil inti desain ruang rawat inap hasil penelitian University Medical Center of Princeton, yang telah terbukti mampu mengurangi penggunaan obat sebanyak $30 \%$, meningkatkan kualitas healing environtment di ruangan dengan elemen pendukungnya seperti penggunaan material kayu dan penggunaan warna yang tepat, membuat layout ruang yang seragam untuk memudahkan dokter dan perawat dalam proses pelayanan, serta mengoptimalkan view pasien ke ruang luar dengan memberi bukaan serta taman hijau di balkon (nytimes.com).

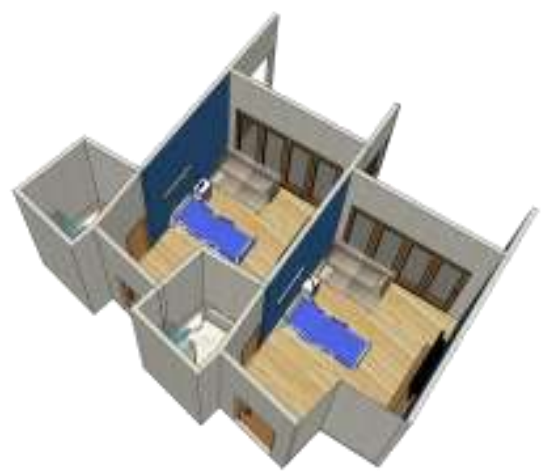

Gambar 6. Ruang Rawat Inap Kelas 1 
2. Ruang Rawat Inap Kelas 2

Ruang rawat inap kelas 2 (Gambar 7) merupakan modifikasi dari dua denah ruang rawat inap kelas 1 yang digabung menjadi satu. Rumah sakit yang direncanakan tidak memiliki ruang rawat inap kelas 3 karena kepadatan yang tinggi dapat menghambat proses penyembuhan pasien.

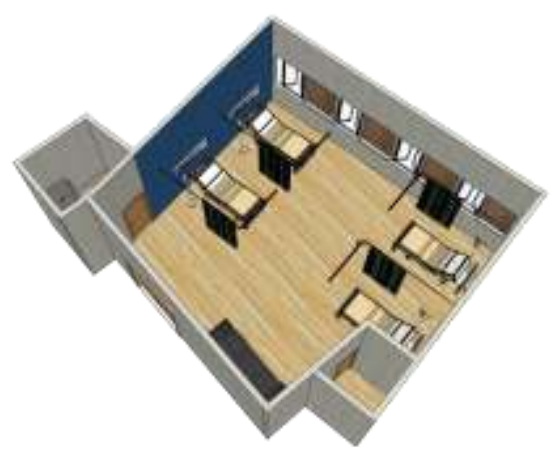

Gambar 7. Ruang Rawat Inap Kelas 2

3. Warna

Warna yang diterapkan adalah warna untuk membantu perwujudan healing environtment yaitu warna yang menenangkan untuk meningkatkan kualitas istirahat pasien (Fontaine dkk, 2001 dalam Sridhar, 2013). Penggunaan warna natural di interior rumah sakit juga dapat membuat efek melegakan dan menenangkan yang meningkatkan kecepatan penyembuhan (Sridhar, 2013). Aplikasi warna pada rumah sakit dijabarkan pada Tabel 3.

Tabel 3. Aplikasi Warna

\begin{tabular}{|l|l|l|}
\hline AREA & \multicolumn{1}{|c|}{ WARNA } & \multicolumn{1}{|c|}{ DAMPAK } \\
\hline Publik & $\begin{array}{l}\text { Menenangkan } \\
\text { dan melegakan } \\
\text { (biru, hijau, } \\
\text { ungu) pada } \\
\text { lobby. }\end{array}$ & $\begin{array}{l}\text { Memberi rasa } \\
\text { menyambut. }\end{array}$ \\
\cline { 2 - 3 } & $\begin{array}{l}\text { Warna cerah } \\
\text { pada pos } \\
\text { perawat. }\end{array}$ & $\begin{array}{l}\text { Memberi kesan } \\
\text { bersahabat dan } \\
\text { bahagia. }\end{array}$ \\
\hline
\end{tabular}

\begin{tabular}{|l|l|l|}
\hline & $\begin{array}{l}\text { Warna hangat } \\
\text { pada koridor. }\end{array}$ & $\begin{array}{l}\text { Memberi kesan } \\
\text { nyaman dan } \\
\text { familiar. }\end{array}$ \\
\hline $\begin{array}{l}\text { Semi- } \\
\text { Privat }\end{array}$ & $\begin{array}{l}\text { Warna netral } \\
\text { pada ruang } \\
\text { tindakan atau } \\
\text { fungsi. }\end{array}$ & $\begin{array}{l}\text { Agar tidak } \\
\text { mengganggu } \\
\text { proses fungsi atau } \\
\text { kegiatan. }\end{array}$ \\
\cline { 2 - 3 } & $\begin{array}{l}\text { Warna natural } \\
\text { pada ruang } \\
\text { non-tindakan. }\end{array}$ & $\begin{array}{l}\text { Memberi kesan } \\
\text { menyatu dengan } \\
\text { alam sesuai } \\
\text { konsep healing. }\end{array}$ \\
\cline { 2 - 3 } & $\begin{array}{l}\text { Warna cerah } \\
\text { pada pos } \\
\text { perawat. }\end{array}$ & $\begin{array}{l}\text { Memberi kesan } \\
\text { bersahabat dan } \\
\text { bahagia. }\end{array}$ \\
\hline Privat & $\begin{array}{l}\text { Warna hangat } \\
\text { pada ruang } \\
\text { rawat inap. }\end{array}$ & $\begin{array}{l}\text { Memberi } \\
\text { ketenangan dan } \\
\text { rasa nyaman. }\end{array}$ \\
\cline { 2 - 3 } & $\begin{array}{l}\text { Warna natural } \\
\text { pada koridor } \\
\text { dan ruang } \\
\text { tindakan. }\end{array}$ & $\begin{array}{l}\text { Memberi kesan } \\
\text { nyaman dan } \\
\text { menyatu dengan } \\
\text { alam. }\end{array}$ \\
\cline { 2 - 3 } $\begin{array}{l}\text { Warna teals, } \\
\text { hijau, dan biru } \\
\text { pada ruang } \\
\text { operasi/bedah. }\end{array}$ & $\begin{array}{l}\text { Memberi kesan } \\
\text { dingin dan } \\
\text { menenangkan } \\
\text { yang dibutuhkan } \\
\text { pada ruang bedah. }\end{array}$ \\
\hline
\end{tabular}

4. Material

Material pada rumah sakit harus tidak berkontribusi terhadap penumpukan Persistent Organic Pollutants, tidak mengandung atau memancarkan bahan berbahaya, merupakan material alami, daur ulang atau dapat didaur ulang, dan tidak diproduksi dengan bahan kimia yang berbahaya (Rossi \& Lent, 2006). Aplikasi material contohnya yaitu karet sintetis, batu, kayu, GRC, dan keramik (Gambar 8). Aplikasi material pada rumah sakit selengkapnya dijabarkan pada Tabel 4.

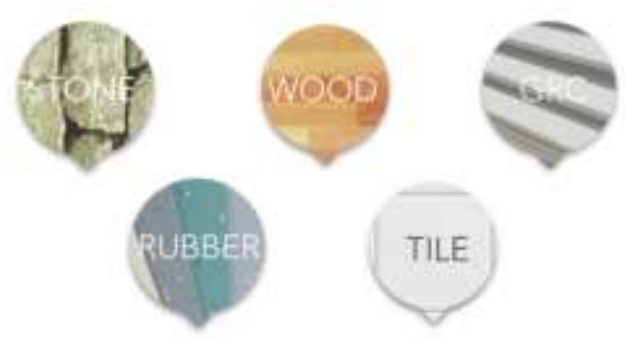

Gambar 8. Jenis Material 
Tabel 4. Aplikasi Material

\begin{tabular}{|c|c|c|}
\hline MATERIAL & JENIS & APLIKASI \\
\hline \multirow[t]{3}{*}{ Lantai } & $\begin{array}{l}\text { Keramik } \\
\text { Putih }\end{array}$ & Area publik. \\
\hline & $\begin{array}{l}\text { Parquet } \\
\text { kayu }+ \\
\text { laminasi }\end{array}$ & $\begin{array}{l}\text { Spot area } \\
\text { publik, ruang } \\
\text { rawat inap. }\end{array}$ \\
\hline & $\begin{array}{l}\text { Karet } \\
\text { Sintetis }\end{array}$ & $\begin{array}{l}\text { Ruang steril, } \\
\text { ICU. }\end{array}$ \\
\hline \multirow[t]{3}{*}{ Dinding } & Keramik & $\begin{array}{l}\text { Area publik, } \\
\text { semi steril, area } \\
\text { mudah kotor. }\end{array}$ \\
\hline & $\begin{array}{l}\text { Karet } \\
\text { Sintetis }\end{array}$ & Area steril. \\
\hline & $\begin{array}{l}\text { Parquet } \\
\text { kayu }\end{array}$ & $\begin{array}{l}\text { Spot area } \\
\text { publik, area } \\
\text { privat. }\end{array}$ \\
\hline \multirow[t]{2}{*}{ Plafon } & GRC & $\begin{array}{l}\text { Area publik, } \\
\text { semi-publik, } \\
\text { rawat inap kelas } \\
2 \text {, zona steril. }\end{array}$ \\
\hline & $\begin{array}{l}\text { Plafon } \\
\text { Kayu }\end{array}$ & $\begin{array}{l}\text { Rawat inap } \\
\text { kelas 1, spot } \\
\text { area publik. }\end{array}$ \\
\hline
\end{tabular}

I. Analisis Struktur

1. Upper structure

Pemilihan sistem struktur yang digunakan berdasarkan pertimbangan:

a. Material atap harus kuat, tidak bocor, tahan lama, dan tidak menjadi tempat perindukan serangga, tikus, dan binatang pengganggu lainnya.

b. Material atap menggunakan material lokal, prefabrikasi, memiliki jejak karbon yang rendah dan tidak mengandung toksik.

Pada area upper structure, rumah sakit menggunakan beton dengan lapisan kedap air, dengan beberapa bagian atap menggunakan roof garden demi mendukung konsep green hospital (Brahic, 2007 dalam newscientist.com). Terdapat juga aplikasi pergola kayu pada hub yang menciptakan kesan hangat dan modern di rumah sakit. Aplikasi kayu juga mendukung konsep green hospital karena kayu dapat menghadirkan kesan alami pada rumah sakit.

2. Super structure

Pemilihan sistem struktur yang digunakan berdasarkan pertimbangan:

a. Material yang digunakan merupakan material lokal, mudah dibersihkan, prefabrikasi, memiliki jejak karbon rendah, dan tidak mengandung toksik.

b. Jika dimungkinkan material pada bangunan yang bukan merupakan area pelayanan menggunakan material bekas bongkaran bangunan yang ada di tapak.

Pada area super structure rumah sakit menggunakan sistem portal dengan sistem kolom dan balok sederhana demi memudahkan proses konstruksi. Material penutup berupa bata ringan, dan penggunaan material hasil bongkaran di beberapa massa area servis. Terdapat juga aplikasi dilatasi kolom pada massa bangunan yang panjang untuk meminimalisir resiko kerusakan bangunan.

3. Sub structure

Pemilihan sistem struktur yang digunakan berdasarkan pertimbangan:

a. Pondasi harus dapat memikul beban bangunan dengan ketinggian bangunan yang direncanakan.

b. Polusi pada proses konstruksi harus minim dan kegiatan konstruksi relatif cepat.

Sistem sub-structure yang digunakan yakni pondasi tiang pancang karena mampu menahan beban bangunan bertingkat banyak, minim polusi karena tidak menggali tanah, proses relatif cepat, dan dengan metode baru, instalasi tiang pancang tidak menimbulkan bising berlebih (Solikhati, 2011). 
J. Analisis Utilitas

1. Utilitas Pencahayaan

Sesuai konsep green hospital, pencahayaan dominan menggunakan pencahayaan alami melalui pengaturan dimensi bangunan dengan kedalaman tidak lebih dari $8,4 \mathrm{~m}$, ketinggian tidak melebihi 3,6 $\mathrm{m}$ dan tidak kurang dari 2,7 m. Selain itu terdapat aplikasi bukaan, atrium, skylight dan jalusi untuk mengoptimalkan penetrasi cahaya matahari (Rahim, 2012). Untuk pencahayaan buatan menggunakan LED dengan switchtimer dan photo-sensor yang dapat mengurangi penggunaan listrik sebesar 9\% (Setyawan, 2012).

2. Utilitas Penghawaan

Sesuai konsep green hospital, penghawaan utama menggunakan penghawaan alami khususnya pada zona publik. Untuk zona steril menggunakan AC Sentral dengan refrigeran hidrokarbon yang lebih ramah lingkungan dan dapat mencapai suhu lebih dingin (Firdaus, 2010). Penerapan refrigeran hidrokarbon juga dapat menurunkan penggunaan listrik untuk penghawaan sebesar $30 \%$ (Setyawan, 2012).

3. Utilitas Instalasi Listrik

Sesuai dengan konsep green hospital maka terdapat pemanfaatan energi alternatif yaitu energi mikro-hidro dari Kali Ciliwung di timur tapak yang menyediakan $20 \%$ daya harian rumah sakit (Wibisono, 2008). Selain itu terdapat aplikasi solar cell yang menyediakan 5\% daya harian rumah sakit (solarpanelindonesia.com).

Terdapat juga instalasi genset penyuplai seluruh kebutuhan daya harian rumah sakit, genset juga disokong dengan UPS sebagai alih daya sementara saat mati listrik.

4. Utilitas Sistem Transportasi

Dirancang untuk meningkatkan performansi bangunan yaitu dengan aplikasi koridor selebar empat meter, bukaan pintu yang memperhitungkan fungsi ruang, serta kemudahan hubungan horizontal antar fungsi. Untuk transportasi vertikal disediakan ramp, lift, dan tangga yang telah disesuaikan dengan standar dan pedoman perancangan rumah sakit.

5. Utilitas Sistem Sanitasi (lihat Tabel 5)

Tabel 5. Utilitas Sistem Sanitasi

\begin{tabular}{|c|c|c|}
\hline SISTEM & JENIS & PENGGUNAAN \\
\hline \multirow{4}{*}{$\begin{array}{l}\text { Air } \\
\text { Bersih }\end{array}$} & PDAM & Kebutuhan air bersih. \\
\hline & $\begin{array}{l}\text { Sumur } \\
\text { dalam }\end{array}$ & $\begin{array}{l}\text { Kebutuhan air bersih } \\
+ \text { perlakuan khusus } \\
\text { untuk air steril. }\end{array}$ \\
\hline & $\begin{array}{l}\text { Air daur } \\
\text { ulang }\end{array}$ & $\begin{array}{l}\text { Penyiram lansekap, } \\
\text { air siram (flush) WC. }\end{array}$ \\
\hline & $\begin{array}{l}\text { Air siap } \\
\text { minum }\end{array}$ & $\begin{array}{l}\text { Air sumur dengan } \\
\text { perlakuan khusus } \\
\text { agar dapat diminum } \\
\text { langsung. }\end{array}$ \\
\hline \multirow[t]{3}{*}{$\begin{array}{l}\text { Air } \\
\text { Limbah }\end{array}$} & $\begin{array}{l}\text { Grey } \\
\text { water }\end{array}$ & $\begin{array}{l}\text { Diolah lagi dengan } \\
\text { IPAL dan digunakan } \\
\text { lagi. }\end{array}$ \\
\hline & $\begin{array}{l}\text { Black } \\
\text { water }\end{array}$ & $\begin{array}{l}\text { Ditampung dan } \\
\text { dikirimkan secara } \\
\text { periodik ke IPLT. }\end{array}$ \\
\hline & $\begin{array}{l}\text { Clinical } \\
\text { water }\end{array}$ & $\begin{array}{l}\text { Perlakuan khusus di } \\
\text { IPAL agar dapat } \\
\text { digunakan lagi. }\end{array}$ \\
\hline \multirow[t]{2}{*}{$\begin{array}{l}\text { Air } \\
\text { Hujan }\end{array}$} & \multirow[t]{2}{*}{ Hujan } & $\begin{array}{l}\text { Ditampung lalu } \\
\text { digunakan untuk } \\
\text { penyiram lansekap } \\
\text { (kelair.bppt.go.id). }\end{array}$ \\
\hline & & $\begin{array}{l}\text { Aplikasi biopori di } \\
\text { tapak mampu } \\
\text { meningkatkan luas } \\
\text { daerah serapan air } \\
\text { sebesar } 42 \text { kali lipat } \\
\text { (biopori.com). } \\
\text { Limpahan air hujan } \\
\text { yang tidak terserap } \\
\text { biopori dialirkan ke } \\
\text { sumur resapan, } \\
\text { limpahan yang tidak } \\
\text { terserap sumur } \\
\text { resapan dialirkan ke } \\
\text { riol kota. }\end{array}$ \\
\hline
\end{tabular}




\section{Utilitas Sistem Pengelolaan Limbah (lihat Tabel 6)}

Tabel 6. Utilitas Sistem Pengelolaan Limbah

\begin{tabular}{|c|c|c|}
\hline $\begin{array}{l}\text { KLASIFI } \\
\text { KASI }\end{array}$ & JENIS & APLIKASI \\
\hline \multirow[t]{3}{*}{$\begin{array}{l}\text { Non- } \\
\text { Medis }\end{array}$} & $\begin{array}{l}\text { Limbah } \\
\text { organik (sisa } \\
\text { dapur, } \\
\text { sampah } \\
\text { domestik) } \\
\end{array}$ & $\begin{array}{l}\text { Diolah dengan } \\
\text { biodigester di area } \\
\text { pengolahan limbah } \\
\text { di rumah sakit } \\
\text { (biologi.lipi.go.id). }\end{array}$ \\
\hline & $\begin{array}{l}\text { Limbah } \\
\text { anorganik } \\
\text { (plastik, } \\
\text { botol kaca) }\end{array}$ & $\begin{array}{l}\text { Dipilah lalu } \\
\text { dikirim ke fasilitas } \\
\text { daur ulang di luar } \\
\text { rumah sakit. }\end{array}$ \\
\hline & $\begin{array}{l}\text { Limbah } \\
\text { organik } \\
\text { (sampah } \\
\text { daun) }\end{array}$ & $\begin{array}{l}\text { Dimasukkan ke } \\
\text { biopori sebagai } \\
\text { unsur pendukung } \\
\text { fungsi biopori } \\
\text { (biopori.com). }\end{array}$ \\
\hline \multirow[t]{6}{*}{ Medis } & $\begin{array}{l}\text { Limbah } \\
\text { benda tajam }\end{array}$ & $\begin{array}{l}\text { Ditampung di } \\
\text { wadah khusus lalu } \\
\text { dimasukkan } \\
\text { incenerator, residu } \\
\text { dibuang ke } \\
\text { landfill. }\end{array}$ \\
\hline & $\begin{array}{l}\text { Limbah } \\
\text { infeksius }\end{array}$ & $\begin{array}{l}\text { Ditampung di } \\
\text { wadah khusus lalu } \\
\text { dimasukkan } \\
\text { incenerator, residu } \\
\text { dibuang ke } \\
\text { pembuangan B3 } \\
\text { atau ke landfill. }\end{array}$ \\
\hline & $\begin{array}{l}\text { Limbah } \\
\text { jaringan } \\
\text { tubuh }\end{array}$ & $\begin{array}{l}\text { Dimusnahkan } \\
\text { dengan } \\
\text { incenerator. }\end{array}$ \\
\hline & $\begin{array}{l}\text { Limbah } \\
\text { sitotoksik }\end{array}$ & $\begin{array}{l}\text { Dikembalikan ke } \\
\text { distributor atau } \\
\text { ditampung dan } \\
\text { dimasukkan ke } \\
\text { incenerator. }\end{array}$ \\
\hline & $\begin{array}{l}\text { Limbah } \\
\text { farmasi }\end{array}$ & $\begin{array}{l}\text { Dikembalikan ke } \\
\text { produsen atau } \\
\text { dimusnahkan di } \\
\text { incenerator. }\end{array}$ \\
\hline & $\begin{array}{l}\text { Limbah } \\
\text { kimia }\end{array}$ & $\begin{array}{l}\text { Limbah cair diolah } \\
\text { oleh IPAL, limbah } \\
\text { kimia padat } \\
\text { dikumpulkan dan } \\
\text { dimusnahkan } \\
\text { incenerator. }\end{array}$ \\
\hline
\end{tabular}

\begin{tabular}{|l|l|l|}
\hline & $\begin{array}{l}\text { Limbah } \\
\text { radioaktif }\end{array}$ & $\begin{array}{l}\text { Dikumpulkan di } \\
\text { kontainer khusus } \\
\text { lalu diantarkan ke } \\
\text { fasilitas } \\
\text { pengolahan yang } \\
\text { telah memenuhi } \\
\text { persyaratan } \\
\text { pengolahan limbah } \\
\text { radioaktif. }\end{array}$ \\
\hline
\end{tabular}

\section{KESIMPULAN (KONSEP DESAIN)}

Konsep rancangan rumah sakit mengacu pada elemen konsep green hospital yaitu kesesuaian lokasi, pemilihan material ramah lingkungan, konservasi air, penanganan limbah yang terpadu, pemanfaatan energi alternatif, efisiensi energi, dan peningkatan performansi yang juga menerapkan standar perancangan rumah sakit sesuai dengan pedoman dari Kementrian Kesehatan Republik Indonesia. Perwujudan healing environtment pada rumah sakit dicapai melalui taman rumah sakit yang mengelilingi massa ruang rawat inap (Gambar 8 dan Gambar 9). Keseluruhan massa bangunan rumah sakit merupakan satu kesatuan fungsi yang dirancang sedemikian rupa sehingga memiliki kualitas lingkungan buatan yang baik serta memiliki performansi bangunan yang tinggi (Gambar 10).

Berdasarkan hasil analisis data serta tinjauan teori, maka diperoleh hasil rancangan Rumah Sakit Umum Kelas B dengan Konsep Green Hospital di Kota Depok sebagai berikut. Lokasi : Jl. Raya Citayam, Depok Luas Lahan : $37.700 \mathrm{~m}^{2}$ Luas Bangunan : $22.000 \mathrm{~m}^{2}$ Daya Tampung : 300 tempat tidur Kegiatan : Pelayanan Kesehatan

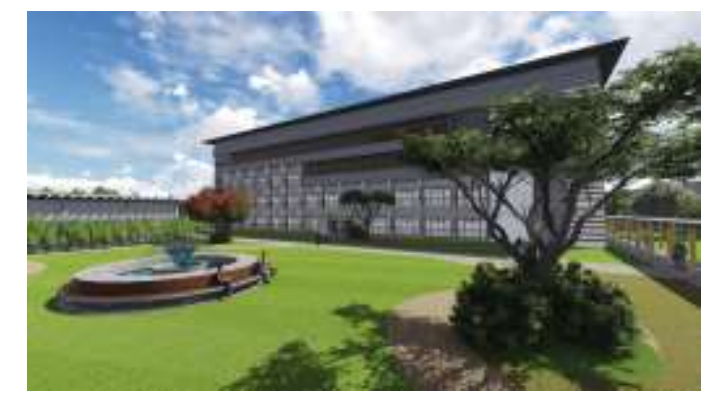

Gambar 9. Taman Rumah Sakit dan Gedung Rawat Inap Kelas 1 


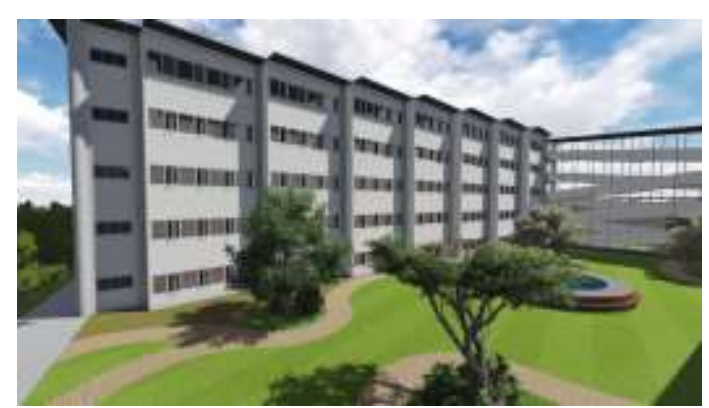

Gambar 10. Taman Rumah Sakit dan Gedung Rawat Inap Kelas 2

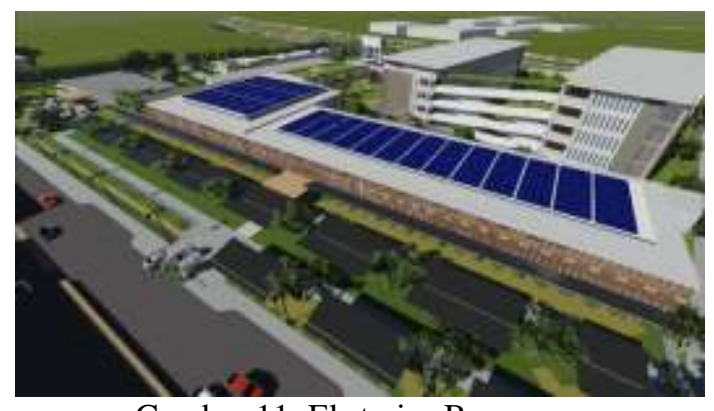

Gambar 11. Eksterior Bangunan

\section{REFERENSI}

Brahic, Catherine. 2007. Cooling Percentage by Green Roof. Amerika: Artikel dalam Jurnal New Scientist.

Firdaus, Aneka. 2010. Analisa Pengaruh Penggunaan Refrigeran Hidrokarbon Musicool-22 Pengganti Freon-22 Terhadap Kinerja Alat Air Conditioning. Palembang: Universitas Sriwijaya

Rossi, Mark \& Lent, Tom. 2006. Creating Safe and Healthy Spaces: Selecting Material that Support Healing. The Center For Health Design: CA

Rahim, H.M. Ramli. 2012. Fisika Bangunan Untuk Area Tropis. Bogor: IPB-Press.

Setyawan, I Putu Gde Weda. 2012.

Manajemen Energi di Rumah Sakit Surya Husada Denpasar. Bali: Universitas Udayana.

Solikhati, Y. 2011. Konstruksi Bangunan: Pondasi-Core. Semarang: Materi Kuliah Program Studi DIII Arsitektur Universitas Diponegoro.
Surtowinoto, Sutarni M. 1997. Flora Eksotika; Tanaman Peneduh. Yogyakarta: Kanisius.

Sridhar, Jarupala. 2013. Color Choices in Healthcare Design and Its Effect on Health and Psychology. India: Hyena Labs Studio

Ulrich, Roger.S. 2002. Health Benefits of Gardens in Hospitals. International Exhibition Florida, Paper for Conference, Plants for People.

Wibisono, Ari. 2014. Studi Perencanaan Pembangkit Listrik Tenaga Mikro Hidro (PLTMH) Di Sungai Soko Desa Olung Siron Kecamatan Tanah Siang Kabupaten Murung Raya Provinsi Kalimantan Tengah. Malang: Universitas Brawijaya.

http://sirs.buk.depkes.go.id/rsonline/report/rep ort_by_catrs.php

http://www.newscientist.com/article/dn12710green-roofs-could-cool-warming-cities.html -

http://www.kelair.bppt.go.id/Sitpa/Artikel/Lim bahrs/limbahrs.html

http://www.biologi.lipi.go.id/bio_indonesia/m Template.php?h=3\&id_berita $=267$

http://www.nytimes.com/interactive/2014/08/2 1/arts/design/a-model-room-becomes-real.html

http://www.biopori.com

http://www.solarpanelindonesia.com

https://sourceable.net/can-facade-design-abetthe-healing-process/ 